\title{
Reduced mutual coupling multiband MIMO patch antenna with swastik type mushroom EBG
}

\author{
Maturi Thirupathi $^{1}$, Baranikunta Harikrishna $^{2}$ \\ ${ }^{1}$ Department of Electronics \& Communication Engineering, Shri Jagdishprasad Jhabarmal Tibrewala University, India \\ ${ }^{2}$ Department of Electronics \& Communication Engineering, CMR Engineering College, India
}

\begin{tabular}{|c|c|}
\hline Article Info & ABSTRACT \\
\hline Article history: & This paper presents a reduced mutual coupling $1 \times 2$ rectangular patch \\
\hline Received Aug 4, 2018 & $\begin{array}{l}\text { antenna. Ine major disadvantage of the } \mathrm{M} \text {. } \\
\text { two antennas are placed nearby mutual coupling occurs. When mutual }\end{array}$ \\
\hline Revised Nov 25, 2018 & coupling occurs decrease the channel capacity. Hence the propose system \\
\hline Accepted Jan 21, 2019 & $\begin{array}{l}\text { which resonates at first } 2.5 \mathrm{GHz} \text {, second is resonates at } 5.4 \mathrm{GHz} \text {. Two closely } \\
\text { spaced antenna elements are separated by a distance of } \lambda \mathrm{max} / 8 \text {. Here Swastik }\end{array}$ \\
\hline Keywords: & $\begin{array}{l}\text { type mushroom EBG is introduced. EBG is placed between the two antennas. } \\
\text { When EBG is placed between the two antennas good coupling reduction is }\end{array}$ \\
\hline $\begin{array}{l}\text { Dual band antenna } \\
\text { EBG }\end{array}$ & $\begin{array}{l}\text { obtained. This design is excellent isolation of }-35 \mathrm{~dB} \text { and }-25 \mathrm{~dB} \text { can be } \\
\text { observed in the simulation results. }\end{array}$ \\
\hline
\end{tabular}

Copyright $@ 2019$ Institute of Advanced Engineering and Science.

Micro strip antenna

Mutual coupling

Return loss

All rights reserved.

\section{Corresponding Author:}

Maturi Thirupathi,

Department of Electronics \& Communication Engineering,

Shri Jagdishprasad Jhabarmal Tibrewala University,

Churela, Rajasthan, India 333001.

Email: thiru5505@gmail.com

\section{INTRODUCTION}

MIMO or Multiple-input, Multiple-output antennas improves the communication performance with multiple transmitters and receivers. MIMO achieves to improve wireless communication system capacity, range and reliability [1]. Multiple inputs refers to multiple transmitter antennas since they input a radio signal into channel and multiple output refers to multiple receiver antennas since they take output from the channel and into the receiver. At lower frequencies the antenna size is large so design criteria are main important [2]. The major disadvantage of a MIMO antenna design is mutual coupling.How to reduce mutual coupling between the closely spaced antenna elements. Now adays MIMO antenna are used in wireless communication systems. But the MIMO antennas are arranged side by side they suffer mtual coupling. So how to reduce the mutual coupling is the major problem in the antenna design. Now am desiging dual band MIMO antenna and Swastik type mushroom EBG (Electronic Band Gap) structure. This EBG structure is used to reduce the mutual coupling [3].

In this work, a dual-band rectangular patch antenna is designed for $2.5 \mathrm{GHz}$ and $5.4 \mathrm{GHz}$. The dualband rectangular patch antenna is used as a single element of a $1 \times 2$ MIMO configuration [4]. Two antenna elements are closely placed $(\lambda \max / 8)$ distance and an isolation of better than $-25 \mathrm{~dB}$ is achieved [5] of wavelength of higher operating band $5.4 \mathrm{GHz}$. Since, the far-field region of the higher band is larger, so how to suppress the mutual coupling for this band [6]. The dual band patch antennas in between swastik type mushroom EBG introduced.so the antenna elements are placed on a common substrate in such a way that it slightly cancels the fields at $5.4 \mathrm{GHz}$ bands from each other leading to lower mutual coupling at higher band Later, a dual-band modified swastika mushroom type EBG is placed in between two antenna elements resulting in excellent isolation in both operating bands [7]. When, MIMO antennas are very close to each 
other when designed. Antennas close to each other mutual coupling occurs. So, it reduces the mutual coupling.different techniques to reduce the mutual coupling. When mutual coupling occurs the total gain decreased. So to increase the gain multiple antennas are used at the transmission side and to receive the signal same antennas are used at the receving side. When, two antennas very close to each other mutual coupling occur. So here two antennas are desined. In higher frequency band coupling occurred. So Swatik type mushroom EBG designed in between two antennas. So mutual coupling is reduced. Total gain with EBG also increased. In wireless communication systems this antenna is useful and good isolation. The paper is organized as follows. Section 2 describes the design of dual-band antenna. Section 3 describes the design of EBG integrated antenna followed by results and conclusion.

\section{PROPOSED DUAL-BAND PATCH ANTENNA}

In this section the proposed dual band patch antenna configuration is discussed. Here, a dual-band single element micro strip patch antenna is designed which is further used to realize a $1 \times 2$ MIMO antenna. The layout of the antenna $1 \times 2$ MIMO is shown in Figure 1 . The proposed antenna is built on a commonly used FR4 substrate of thickness $1.6 \mathrm{~mm}$ and dielectric constant of 4.4. Initially, band $2.5 \mathrm{GHz}$ rectangular microstrip patch antenna is designed. Dimensions, width $(\mathrm{W})$, and length $(\mathrm{L})$ of the conventional rectangular patch antenna is calculated using the following expressions

$$
\begin{aligned}
& W=\frac{c}{2 f_{0} \sqrt{\frac{(\varepsilon+1)}{2}}} \\
& L=\frac{c}{2 f_{0} \sqrt{\varepsilon_{\text {eff }}}}-0.824 h \frac{\left(\varepsilon_{\text {eff }}+0.3\right)\left(\frac{W}{h}+0.264\right)}{\left(\varepsilon_{\text {eff }}-0.258\right)\left(\frac{W}{h}+0.8\right)}
\end{aligned}
$$

The substrate dimensions of the ground plane are equal to width and length. Thereafter, an optimized thin rectangular slot is placed along the length of the rectangular patch to excite another $5.4 \mathrm{GHz}$ band [8]. By inserting rectangular slots into patches dual-band operation is achieved. However, incorporating a slot into the patch shift the actual operating frequency of conventional $5.4 \mathrm{GHz}$ band, as shown in Figure 2 . Thus, the length $(\mathrm{L})$ of the patch and length of the slot is precisely optimized to achieve exact $2.5 \mathrm{GHz}$ and $5.4 \mathrm{GHz}$ bands. It is evident that the optimized length of the patch and length of the slot meet the exact desired $2.5 \mathrm{GHz}$ and $5.4 \mathrm{GHz}$ bands.Using the length and width dimensions the antennas are designed. Here without EBG structure coupling is occur [9]. Figure 2 shows the frequency versus return loss. This graph shows the coupling at higher frequency and gain is also less compare to the with EBG structure. The gain of the array antenna is shown in Figure 3. Without EBG. Without EBG structure the gain will be less. The total gain is less compared to the with EBG total gain. Using the dimensions the micro strip antenna resonates dual band of frequencies that frequencies are $2.5 \mathrm{GHz}$ and $5.4 \mathrm{GHz}$.

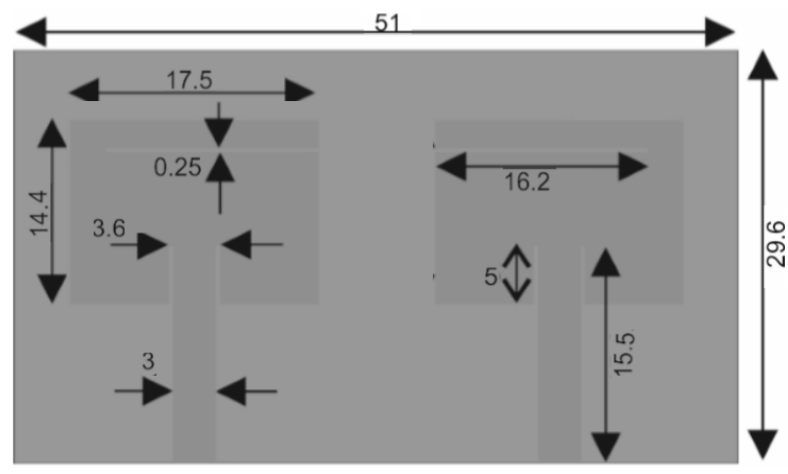

Figure 1. Dual band MIMO antenna

Figure 2 shows return loss Vs frequency without EBG. Without EBG structure at higher frequency band i.e $5.4 \mathrm{GHz}$ frequency mutual coupling occur. In low frequency band $2.4 \mathrm{GHz}$ there is no mutual coupling. So in high frequency band to reduce the mutual coupling. Figure 3 shows the total gain of antenna 
array. Here due to mutual couplig the total gain is reduced. So to increase the gain designed Swasik type mushroom EBG designed.

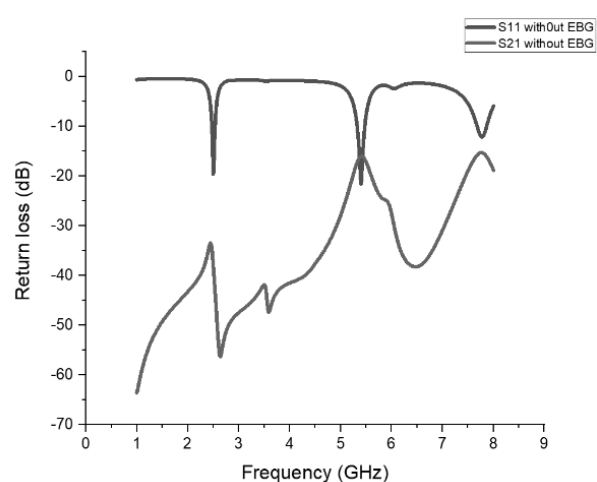

Figure 2. Return loss vs frequency without EBG structure

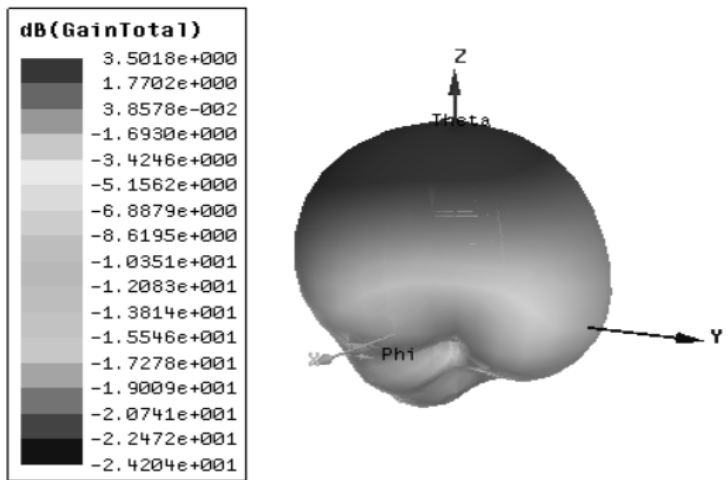

Figure 3. Gain of an array antenna without EBG

\section{EBG STRUCTURE}

In this section, the configuration of the EBG structure is discussed. A dual-band swastik type mushroom EBG is placed between two dual-band antennas separated by a distance of $\lambda \mathrm{max} / 8$, as shown in Figure 4.A swastika type mushroom EBG structure is used as a basic structure to construct a dual-band, swastik mushroom type EBG, both top, and bottom metal plates are shorted through a via at the center are utilized for band-rejection [10]. The upper metal plates are shorter which are used to create a band-gap for upper $5.4 \mathrm{GHz}$ band. A larger single bottom plate is used to reject the lower $2.5 \mathrm{GHz}$ band. However, dimensions of both plates are precisely optimized to obtain the exact frequency bands. Moreover, when the EBG structure is placed between antennas it also alter the operating frequency of the dual-band antenna [11]. Thus, the EBG structure and antenna dimensions are synchronously optimized to obtain the desired frequency bands. Dual band MIMO antenna with EBG structure as shown in Figure 4.

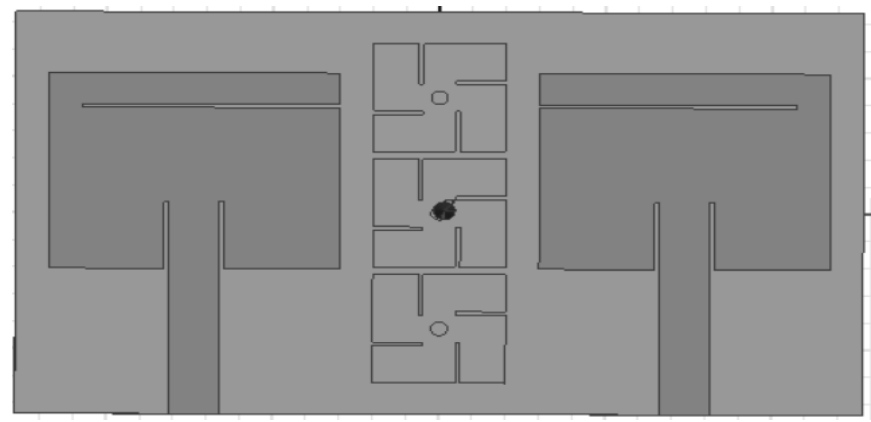

Figure 4. Dual band MIMO antenna with EBG structure

Initially patch antenna designed. After one slot introduced in the patch antenna. That slot resonates another band of frequency. Same antenna designed slot oppositely inserted. Both antennas are resonated same frequency bands. Due to two antennas mutual coupling occur. So reduce the mutual coupling designed swasik type mushroom EBG. This EBG structure in between two antennas inserted. So excellent mutual coupling reduction is obtained. Previously without EBG structure mutual coupling occur. When two antennas on same substrate with EBG structure reduced the mutual coupling.when multiple antennas are used gain will be automatically increased. So MIMO antennas are used. The antenna resonates $2.5 \mathrm{GHz}$ and $5.4 \mathrm{GHz}$. Higher frequency $5.4 \mathrm{GHz}$ the mutual coupling occur. So designed Mush room type swasik EBG designed. Higher frequency band $5.4 \mathrm{GHz}$ reduced the mutual coupling. When reduced the mutual coupling gain is automatically increased. The band rejection property of the dual-band EBG structure can be explained 
through mutual coupling $\left(\mathrm{S}_{21}\right)$ between antennas [12]. The mutual coupling of antennas with EBG is shown in Figure 5. Both antennas are resonating at $2.5 \mathrm{GHz}$ and $5.2 \mathrm{GHz}$ bands resulting in strongest radiation intensities in these two bands. Due to which the MIMO configuration is suffering from strongest mutual coupling in $5.4 \mathrm{GHz}$ band, as evident in Figure 2. (For without EBG configuration) [13]. It is noted that 5.4 $\mathrm{GHz}$ has smaller near field region. In $5.4 \mathrm{GHz}$ band experience stronger mutual coupling compared to 2.5 $\mathrm{GHz}$ band without EBG configuration. This is due to the placement of antenna elements in mirror-image position resulting in current flow $180^{\circ}$ out of phase in each element at $5.4 \mathrm{GHz}$ band leading to better isolation. As the EBG structure is placed between antennas, the mutual coupling is sharply reduced in both operating bands which confirms the dual-band rejection characteristics of the proposed EBG structure [14]. Moreover, as the EBG structure is placed between antennas, it slightly shift the operating frequency in both operating bands [15]. The gain of the antenna array is shown in Figure 6 with EBG structure.

The proposed EBG structure consists of slots loaded in surface which is evolved from the typical swastik Mushroom-EBG structure. The EBG structure is connected to the ground through a probe to form a surface wave on the surface of the EBG structure.The performance and dimensions of the swasik type mushroom EBG structure are simulated by the use of High Frequency Structure Simulator (HFSS).

\section{RESULTS AND DISCUSSION}

Here designed reduced mutual coupling MIMO antenna with swastika type mushroom EBG structure in Figure 4. The results are excellent. Reduced mutual coupling at higher frequencies using swastik type EBG structure inserted between the antennas. The reduced mutual coupling shown in Figure 5. At frequencies $2.4 \mathrm{GHz}$ and $5.4 \mathrm{GHz}$ there is no mutual coupling. The ouput return losses are $-35 \mathrm{~dB}$ and $-25 \mathrm{~dB}$. The total gain is also increased around $3.9 \mathrm{~dB}$.The total gain shown in Figure 6 .The result is there is no mutual coupling between S11 and S12. the discussion is designed simple EBG structure designed .So many coupling mechanism are there nowdays like DGS (defected ground structure), Decoupling network, Meta materials, parasititic elements but this EBG structure is simpe to design. Using HFSS designed the dual band microstrip antenna and calculated s11 and s12.

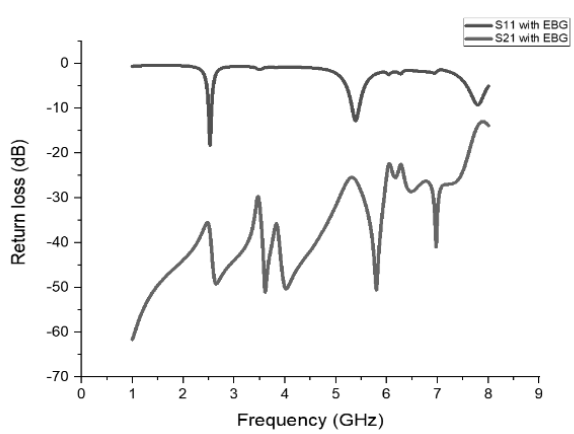

Figure 5. Frequency vs return loss with EBG structure
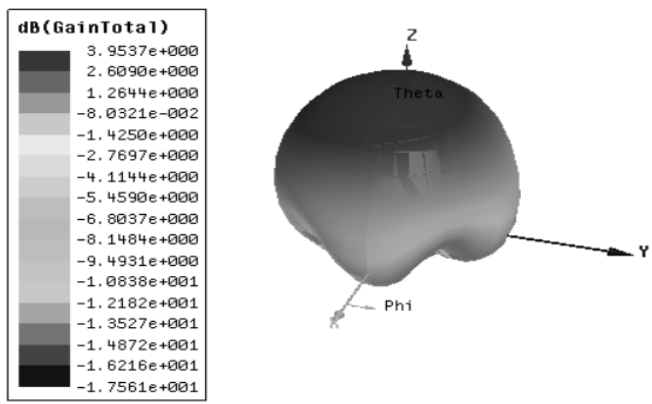

Figure 6. Gain of an array antenna with EBG

\section{CONCLUSION}

This paper presents a reduced mutual coupling using a swastik type mushroom EBG structure. The swastik type mush room EBG structure reduced the mutual coupling. Mutual Coupling between the two rectangular patch antennas is decreased by inserting swatik type mushroom EBG. The proposed EBG structure is simple and easy to fabricate. The antenna has been designed for easy integration with existing wireless communications. A MIMO Microstrip patch antenna has been successfully designed with EBG. It can be concluded from the above results, while designing, a proper feed network and impedance matching are very important parameters in Microstrip patch antenna design. Good isolation is suitable for communications. These frequencies $2.5 \mathrm{GHz}$ and $5.4 \mathrm{GHz}$ are suitable for various wireless communication systems.

\section{REFERENCES}

[1] Yusnita, R., Jodi, W., Elsa, S. "Characteristic MIMO 2x4 Antenna for 5G communication system”, TELKOMNIKA Telecommunication, Computing, Electronics and Control, vol 16, no 4, pp. 1838 1845, 2018. 
[2] Murtala, A. b., et al., "Design of Miniaturized multiband patch antenna using CSRR for WLAN/WiMAX applications", TELKOMNIKA Telecommunication, Computing, Electronics and Control, vol 16, no 4, pp. 1838-1845. 2018

[3] Nooshin, f., Farzad, M., and Anahita, G. "Optimized microstrip antenna with metamaterial superstrates using particle swarm optimization". Bulletin of Electrical Engineering and Informatics. pp. 123 131, 2013

[4] Wang, H., Fang, D. G., and Wang, X. L., "Mutual coupling reduction between two microstrip patch antennas by using the parasitic elements", Microwave Conference; p. 1-4, 2008.

[5] Islam, M. T., Alam, M. S., "Compact EBG structure for alleviating mutual coupling between patch antenna array elements", Progress in Electromagnetics Research, pp.425-38, 2013.

[6] Xiao, S., Tang, M. C., Bai, Y. Y., Gao, S., Wang, B. Z., "Mutual coupling suppression in microstrip array using defected ground structure", Microwaves, Antennas and Propagation.vol. 5, no. 12, pp. 1488-94, 2011.

[7] Yu-Ting, W., Chu, Q. X., "Dual-band multiple input multiple output antenna with slitted ground", Microwaves, Antennas and Propagation. vol. 8, no. 13, pp. 1007-13.

[8] Chiu, C. Y., Cheng, C. H., Murch, R. D., Rowell, C. R., "Reduction of mutual coupling between closely-packed antenna elements", IEEE Transactions on Antennas and Propagation.vol. 55, no. 6, pp.1732-8, 2007.

[9] Diallo, P., et al., "A new method to increase the portto-port isolation of a compact two-antenna umts system", (IEEE Antennas and Propagation Letters), March 2009.

[10] Suntives, A., and Abhari, R., "Miniaturization and isolation improvement of a multiple-patch antenna system using electromagnetic band gap structures," Microwave and Optical Technology Letters, vol. 55, no. 7, pp. 1609-1612, 2013.

[11] Mohamad, Y., and Nader, K., "Design of a band notched Ultra wideband antenna by means of EBG structure", IEEE Antenna propagation letters, vol. 10, pp. 170-173, 2011.

[12] Peng, L., Ruan, C. L., and Xiong, J., "Compact EBG for multi-band applications", IEEE transaction on Antennas and Propagation, vol. 60, pp. 4440-4444, 2012.

[13] Chiu, C. Y., Cheng, C. H., "Reduction of mutual coupling between closely-packed antenna elements", IEEE Trans Antennas Propag. vol 55, no. 6, pp. 1732-8, 2007.

[14] Xiang, Z., Quan, X., and Li, R., "A dual-broadband MIMO antenna system for GSM/ UMTS/LTE and WLAN handsets", IEEE Antennas Wireless Propag Lett, vol. 11, pp. 551-4, 2012.

[15] Khan, M. S., Capobianco, A. D., Najam, A. I., Shoaib, I., Autizi, E., Shafique, M. F., "Compact ultra-wideband diversity antenna with a floating parasitic digitated decoupling structure", IET Microwaves, Antennas and Propagation.vol. 8, no. 10, pp.747-53, 2014. 